\title{
Monitorización de variables medioambientales y energéticas en la construcción de viviendas protegidas: Edificio Cros-Pirotecnia en Sevilla
}

\author{
Monitoring environmental and energy variables in the \\ construction of subsidised housing: Cros-Pirotecnia building \\ in Sevilla
}

$\underline{\text { A. L. León }}^{(*)}$, S. Muñoz ${ }^{(*)}$, J. León $n^{(*)}$, P. Bustamante ${ }^{(*)}$

\section{RESUMEN}

Este trabajo forma parte del proyecto de investigación Efficacia: Reducción del consumo energético y del impacto ambiental en la construcción de viviendas protegidas en Andalucía. Dicho proyecto tiene como objeto de estudio el edificio de viviendas protegidas de Cros-Pirotecnia, emplazado en el Barrio "Pirotecnia" del Distrito Sur de la ciudad de Sevilla. Uno de los objetivos de este trabajo es conocer la demanda y consumo energético, en tiempo real, de este conjunto de viviendas en régimen de alquiler. Para tener en cuenta la influencia de sus habitantes, los resultados obtenidos mediante la instalación de monitorización se ha complementado con una serie de encuestas sobre los hábitos de consumos de sus inquilinos.

En este artículo se describe la metodología empleada para la monitorización y se presentan los principales resultados obtenidos, una vez transcurridos doce meses desde el comienzo del período de medida. Asimismo, se ofrecen los resultados más significativos de las encuestas realizadas a los inquilinos.

$113-96$

Palabras clave: Monitorización, demanda energética, eficiencia energética, ahorro energético, viviendas protegidas.

\section{SUMMARY}

This work is part of the research project known as Efficacia: Reduction of energy consumption and environmental impact of the construction of subsidised housing in Andalusia. The aim of this project is the study of the subsidised housing building Cros-Pirotecnia, located in the "Pirotecnia" neighbourhood of the South District of the city of Seville. One of the objectives of this work is to establish the energy demand and consumption, in real time, of this set of leased housing. The results of the monitoring implemented to take into account the influence of its inhabitants has been complemented with a series of questionnaires on the consumption habits of its tenants.

This article describes the methodology employed for the monitoring and presents the main results obtained, once twelve months have elapsed from the start of the measurement period, as well as the most significant results of the questionnaires carried out among the tenants of these buildings.

Keywords: Monitoring, energy demand, energy efficiency, energy saving, subsidised buildings.

\footnotetext{
(") Instituto Universitario de Arquitectura y Ciencias de la Construcción de la Universidad de Sevilla (IUACC), España 


\section{INTRODUCCIÓN}

El proyecto de investigación denominado Efficacia tiene como principal objetivo incidir en la construcción de edificios de viviendas protegidas de mayor calidad en Andalucía, utilizando criterios compositivos y constructivos encaminados a reducir su demanda energética y su impacto ambiental. Lo llevan a cabo un grupo de investigadores, principalmente arquitectos pertenecientes a la Universidad de Sevilla, y responsables de I+D de empresas tanto públicas como privadas. En concreto, en el proyecto participan el Instituto Universitario de Arquitectura y Ciencias de la Construcción de la Universidad de Sevilla (IUACC), la Empresa Municipal de Vivienda, Suelo y Equipamiento de Sevilla (EMVISESA) y la promotora privada SODINUR S.L.

Los trabajos del Proyecto Efficacia comenzaron en octubre de 2007 y finalizan en septiembre de 2009 (2 años). Está financiado por las empresas EMVISESA y SODINUR S.L. a través de la Corporación Tecnológica de Andalucía (CTA) de la Consejería de Innovación, Ciencia y Empresa de la Junta de Andalucía. El objetivo principal de esta entidad es potenciar la colaboración entre el entorno científico y el productivo, como forma de dar respuesta a las necesidades de innovación y desarrollo de la sociedad andaluza.

Entre los objetivos específicos del proyecto están el establecer un método de aproximación, en el diseño de los edificios, a la eficiencia energética, rentabilizar las actuaciones edificatorias en el ámbito del ahorro de energía, conseguir la mejor relación inversión-resultados y buscar caminos para obtener las mejores prestaciones en materia de eficiencia o calificación energética.

Inicialmente, pretende aplicarse a viviendas protegidas en la zona climática B4 (Sevilla), si bien pretende marcar el camino para estudios similares en otras zonas climáticas.

\section{OBJETIVOS DE LA MONITORIZACIÓN}

Para la consecución de los objetivos anteriores, se ha seguido una metodología con unas actividades planificadas a lo largo de ocho etapas. Una de las tareas principales de este proyecto ha sido la monitorización de un conjunto de viviendas, con el objeto de analizar y parametrizar su demanda y consumos energéticos.

El edificio objeto de estudio es un bloque de viviendas en manzana cerrada, denominado Cros-Pirotecnia (Figuras 1 y 2) que alberga 218 viviendas, locales comerciales y garaje, y que se localiza en la Manzana R-3 del PERI-SU-2 Cros-Pirotecnia. Este edificio, promovido por EMVISESA dentro del Plan Municipal de Viviendas del Ayuntamiento de Sevilla, fue proyectado por los arquitectos Pablo Canela Jiménez, Luis Ureta Tejero y José Manuel Sánchez-Carrero León, y construido en el año 2005 con la normativa de aplicación anterior a la entrada en vigor del Código Técnico de la Edificación. Todas las viviendas están en régimen de alquiler lo que ha facilitado la implementación de los sistemas y equipos para la medida, así como el registro de las distintas variables medioambientales y parámetros energéticos.

Frecuentemente nos encontramos con ejemplos de monitorización de edificios cuyo objetivo consiste en controlar la demanda energética de los mismos para así racionalizar su consumo, aunque la gran mayoría de ellos se centran básicamente en consumos eléctricos.

Los objetivos de la monitorización han sido básicamente los siguientes:

- Utilizar los sistemas implementados para prever el comportamiento energético de los edificios y reducir su consumo energético, así como el impacto ambiental desde la fase de diseño. Por ello, una de las novedades que supone el sistema de monitorización empleado es el de no utilizarlo únicamente como elemento de control sobre el gasto energético, sino el de ser un elemento activo dentro de una metodología estratégica en el diseño de edificios de bajo consumo.

- Registrar y analizar las medidas de las variables medioambientales y de los consumos energéticos realizadas in situ a lo largo de un año (auditoría energética), en una situación real de ocupación, a diferencia de otros métodos alternativos en los que, para evitar las posibles perturbaciones que introducen los usuarios, se realiza sobre viviendas sin ocupar, estableciendo determinados protocolos de comportamiento de los usuarios.

- Complementar la monitorización con una serie de encuestas sobre los hábitos de consumo de los inquilinos de las viviendas objeto de estudio, con la finalidad de obtener correlaciones entre los consumos energéticos y dichos patrones de comportamiento.

- Utilizar la combinación de la monitorización y de las encuestas como referencia real para calibrar y validar los modelos y métodos informáticos de simulación energéticos que se han elaborado en dicho proyecto de investigación, a partir del conocimiento real del comportamiento energético de las viviendas monitorizadas. La calibración de dichos modelos permitirá trabajar con modelos fiables para conocer la efectividad de las nuevas propuestas estratégicas que se 
aportan en dicho proyecto y que están destinadas a reducir la demanda energética de las viviendas objeto de estudio.

\section{ANTECEDENTES SOBRE MONITORIZACIÓN DE VIVIENDAS}

En los últimos años han sido realizadas distintas experiencias de monitorización de edificios de viviendas. Muchas de ellas se describen en documentos de agencias internacionales de energía (1). Señalamos a continuación algunas que consideramos de interés en relación a los objetivos de este trabajo.

En 1993, en Finlandia, se realizó un estudio sobre 400 viviendas para investigar la variación del consumo eléctrico anual, monitorizando únicamente el consumo de receptores eléctricos (fundamentalmente electrodomésticos), sin incluir la iluminación. En estos estudios se obtuvo el consumo típico de una vivienda en $\mathrm{kWh}$ y posteriormente sirvió para desarrollar el programa denominado "Electricity Doctor", mediante el cual los usuarios podían hacer una auditoría energética de sus viviendas a través de internet.

En Holanda, el ECN (2) (Energy Research Centre of the Netherlands) construyó cuatro viviendas adosadas en la localidad holandesa de Petten, dentro del proyecto de investigación denominado "Ecobuild Research Proyect" (3), cuyo primer objetivo es reducir el consumo energético al $50 \%$ respecto a los estándares holandeses.

En Reino Unido destacan varias experiencias (4) entre las que destacan los estudios del Enviromental Change Institute de la Universidad de Oxford, el programa de monitorización de la Electricity Association's Load Research Group (EALRG) centrado en el consumo de electrodomésticos, el estudio "Billsavers" de 1992, donde se monitorizó el consumo de la iluminación y electrodomésticos durante 12 meses en 100 hogares de bajos ingresos de Edimburgo, y, por último, los trabajos realizados en la ciudad de Bath con la participación de 120 familias.

La administración escocesa, durante el año 2005, ha desarrollado las HEED (Home Energy Efficiency Database) que integra el seguimiento de las instalaciones térmicas de las viviendas y las encuestas a los usuarios, para realizar un análisis del consumo energético y adoptar estrategias de eficiencia energética (5).

En Polonia, con el objetivo de validar los modelos de simulación y calibrar el software, se monitorizó la demanda energética
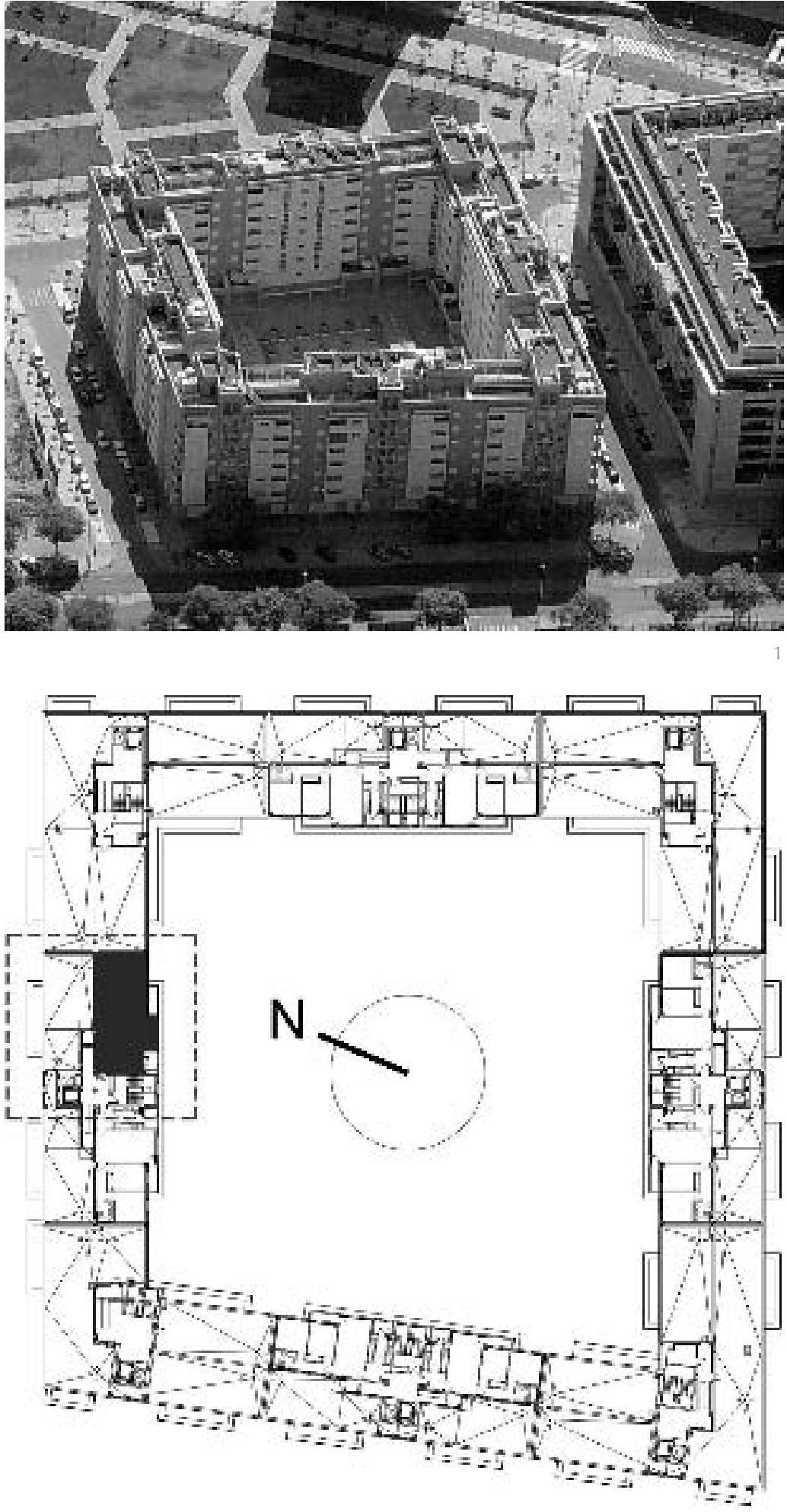

para calefacción y de los flujos de aire en un edificio de viviendas plurifamiliar de cinco plantas localizado en área urbana. La medida del consumo se realizó modificando el sistema de calefacción de la vivienda sustituyéndolo por calentadores eléctricos para facilitar las medidas de consumo (6).

En Rusia, entre 2001 y 2003 se llevaron a cabo los trabajos de monitorización de un 


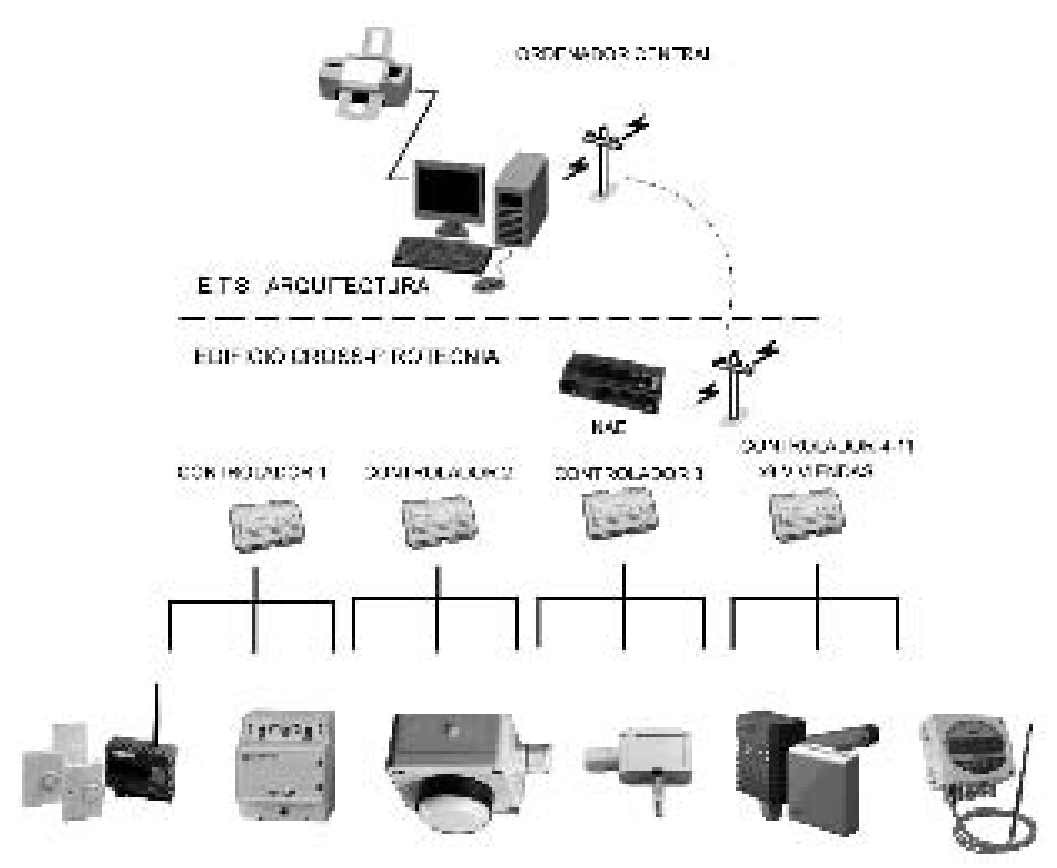

3. Red Metasys con NAE. bloque de viviendas situado en Torzhkovskya (San Petersburgo) (7), dentro de un consorcio internacional liderado por la compañía danesa Velux Internacional. Su objetivo era medir el cambio del consumo energético experimentado de este edificio tras su rehabilitación, durante una temporada de calefacción, respecto de un bloque próximo de referencia de idéntico tamaño y función pero sin rehabilitar. En España destacan los trabajos de INDEL, la monitorización de viviendas en el Parque Goya (8) y del Barrio de Valdesparteras (ambos en Zaragoza), la monitorización de viviendas unifamiliares en Caparroso (Navarra) y el proyecto europeo ENERinTOWN en el que participa como socio el Ente Vasco de la Energía (EVE). Finalmente, el CIEMAT ha analizado y monitorizado en condiciones reales de uso, durante el año 2005, el consumo energético, el confort de los usuarios y el respeto al medio ambiente de 21 viviendas (de un total de 156) en la parte Oeste del barrio de San Fermín (Madrid), las cuales fueron proyectadas de forma bioclimática. En tres parcelas analizadas (5, 12 y 15) se han contrastado los datos facilitados por el Instituto Nacional de Meteorología (INM) con los obtenidos por los investigadores del CIEMAT (9). También ha llevado a cabo la monitorización de dos bloques de viviendas en San Cristóbal de los Ángeles (Madrid) para evaluar su comportamiento energético en condiciones reales de uso (10).

\section{INSTALACIÓN DE MONITORIZACIÓN}

Para la implantación de las instalaciones y equipos necesarios para la monitorización, se ha seleccionado un grupo de viviendas del edificio, cuyo comportamiento fuera lo más representativo posible del conjunto. La elección se ha realizado en función de las distintas orientaciones existentes en el edificio, así como de las distintas configuraciones respecto de la envolvente térmica (viviendas con y sin cubierta). La muestra finalmente elegida está compuesta de ocho viviendas, cuatro en última planta (cubierta) con orientaciones predominantes Norte, Sur, Este y Oeste y cuatro en plantas intermedias con idénticas orientaciones.

Con ayuda de un sistema de monitorización multi-paramétrico denominado Metasys (Figura 3) (11), en las ocho viviendas seleccionadas, en condiciones reales de uso y en tiempo real, se han medido variables medioambientales (temperatura, humedad relativa, niveles de $\left.\mathrm{CO}_{2}, \ldots\right)$, consumos energéticos (agua caliente, calefacción, climatización, energía eléctrica), y se han registrado variables que dan información sobre las condiciones de uso de las viviendas (detectores de presencia y contactores magnéticos en las ventanas, etc.). Esta información nos ha servido para extrapolar los resultados al resto de las viviendas. Además, el sistema de monitorización se ha extendido a otras partes del edificio, como son las zonas comunes (pasillos y cajas de escalera), garaje y la azotea, lugar este último donde se ha situado una estación meteorológica.

En la instalación del sistema de monitorización se ha seguido lo dispuesto en el protocolo indicado por la norma UNE-EN ISO 7726:2002 (12) y se ha considerado, para la lectura de los valores monitorizados y la realización de tendencias históricas, un intervalo de tiempo de 10 minutos.

Todos los datos son registrados por data loggers, los cuales transmiten las señales digitales a un motor de automatización de red que procesa la información y la envía a un ordenador central que procesa y almacena todos los datos obtenidos, mediante un software específico.

Por lo que se refiere a la monitorización individual de las variables medioambientales de cada una de las viviendas, se han incluido registros de temperatura ambiente mediante dos sondas de temperatura, una en la zona de día y otra en la zona de noche; registros de temperatura en los cerramientos mediante sondas de temperatura tanto en la cara interior como en la exterior de cerramientos y cubiertas, con el fin de poder valorar su inercia térmica; registros de humedad en el ambiente mediante dos sondas de humedad relativa, una en la zona de día y otra en la zona de noche; registros de la calidad del 


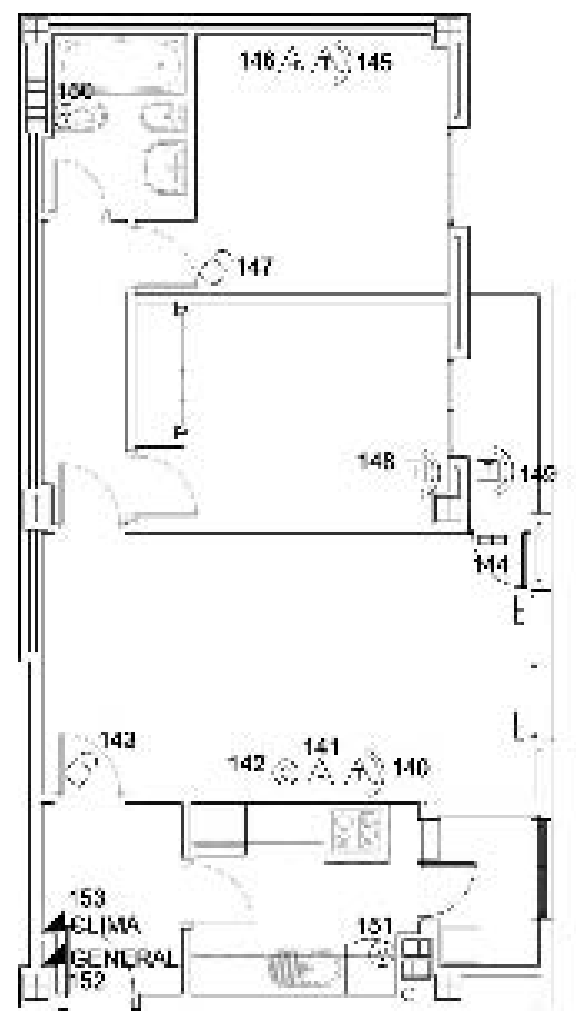

aire mediante sonda de $\mathrm{CO}_{2}$ y registros de velocidad y caudal del aire en los conductos de ventilación.

Para la determinación de los consumos energéticos, se han instalado en cada vivienda dos contadores de energía eléctrica, uno del consumo total y otro para discriminar el consumo eléctrico de los equipos de climatización, así como un contador de consumo de agua caliente sanitaria y una sonda de temperatura de agua caliente sanitaria (ACS).

También se han instalado dispositivos que registran el comportamiento de los usuarios, para determinar las conductas reales de los mismos y su incidencia en las variables medioambientales y en los consumos energéticos. Para ello se han instalado detectores de presencia, tanto en la zona de día como en la de noche, y contactores de ventana que nos indican si las mismas están abiertas o cerradas, lo que incidirá notablemente sobre la ventilación de la vivienda y, en consecuencia, sobre todas sus variables medioambientales.

En la Figura 4 se detalla el esquema de la instalación en una de las viviendas objeto de la monitorización.

Estos dispositivos de control específicos de las viviendas, se han complementado con otros que registran las variables medioambientales en el exterior y en las zonas comunes del inmueble.

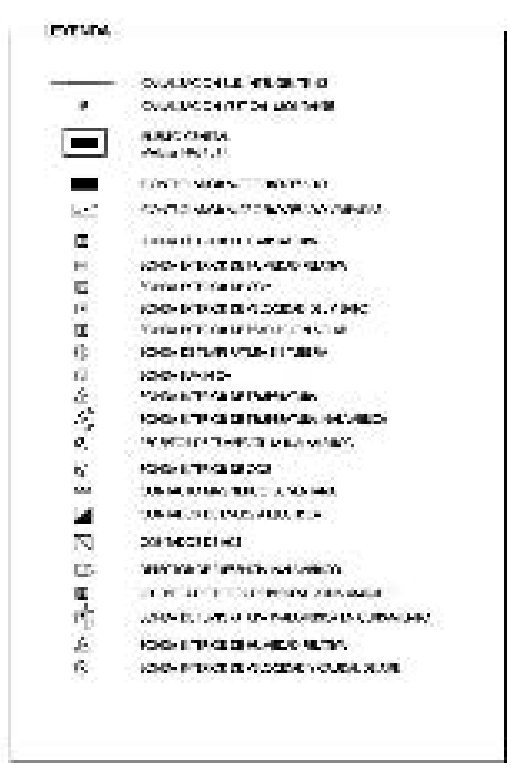

Entre los primeros se cuenta con una estación meteorológica, compuesta por una sonda de temperatura de ambiente exterior, protegida de la radiación solar, en cada una de las orientaciones del edificio (norte, sur, este y oeste); dos sondas de humedad relativa exterior, una en el norte y otra en el sur; una sonda ambiente de $\mathrm{CO}_{2}$ para determinar la calidad del aire exterior; una sonda de velocidad del viento y una sonda de radiación solar.

Entre los segundos que se disponen para las zonas comunes, destacamos aquellos que ofrecen información sobre temperatura ambiente de las zonas comunes (pasillos y vestíbulos), así como sobre niveles de iluminación y consumos eléctricos de esas zonas comunes y del garaje.

Por otro lado, además del control individualizado del ACS de cada vivienda, también se ha monitorizando la instalación centralizada de energía solar térmica para contribución de esta última. Este conjunto de equipos está formado por cinco sondas de temperatura de inmersión: la primera mide la temperatura del agua fría de la red, la segunda salida de los captadores solares, y las tres últimas controlan la temperatura del agua a distintas alturas en el interior de los depósitos acumuladores, con objeto de conocer la estratificación térmica.

El número de dispositivos de control instalados se resume en la Tabla 1, pág. siguiente. 
Tabla 1

Cuadro resumen de las señales de la monitorización.

\begin{tabular}{|c|c|c|c|c|c|}
\hline $\begin{array}{l}\text { DISPOSITIVOS DE CAMPO } \\
\text { finteriores yio exteriores) } \\
\text { (Total } 1 \text { E5 unidades) }\end{array}$ & $\begin{array}{l}\text { ESTACION } \\
\text { METEORO- } \\
\text { LóGICA }\end{array}$ & GARAJE & $\begin{array}{c}\text { ZONAS } \\
\text { COIUNES Y } \\
\text { ACS SOLAR }\end{array}$ & $\begin{array}{l}\text { WMENDAS } \\
\text { INTERMEDIAS } \\
\text { (Sin cubierta) }\end{array}$ & $\begin{array}{l}\text { VVIENDAS } \\
\text { SUPERIORES } \\
\text { (Can cubicrta) }\end{array}$ \\
\hline Sonds temeeraturg amblante & 4 & & 4 & 20 & 18 \\
\hline Sands de radiación solar & 1 & & & & \\
\hline Sonda de veloctead del alrs & 1 & & & 7 & $\mathrm{~g}$ \\
\hline Sonda de $\infty$, & 1 & & & 4 & 4 \\
\hline Sonda de humadad relatwa & 2 & & & s & a \\
\hline Sonta ds tsmperatura de sgua & & 1 & 4 & 4 & 4 \\
\hline Sorda da iluminacion 1 & & 2 & 4 & & \\
\hline Detecter de presencia & & & & 8 & 8 \\
\hline Contector de wentrine & & & & 4 & 4 \\
\hline Contyder de eiecticictad & & 1 & & 5 & 7 \\
\hline Centadar de agus caliente sanite ria & & & & 4 & 4 \\
\hline Total dispssitivos por gnupos & 9 & 4 & 12 & 65 & 85 \\
\hline
\end{tabular}

\section{RESULTADOS DE LA MONITORIZACIÓN}

La campaña de monitorización que se presenta comprende desde el 1 de octubre de 2008 hasta el 31 de octubre de 2009 (trece meses consecutivos). Los datos recibidos, una vez almacenados, son procesados para poderlos interpretar en hojas de cálculo estándar tipo Microsoft Excel 2007® u Open Office Calc 3.1.0®.

\subsection{Temperaturas exteriores}

En la Figura 5 se presentan las temperaturas exteriores medias, tanto diarias como mensuales, medidas por la sonda exterior norte en el periodo monitorizado. Estos registros se comparan con los valores establecidos por los documentos del CTE para la ciudad de Sevilla (13) y con los datos meteorológicos históricos procedentes de la Agencia Estatal de Meteorología (AEMET), para el período del año 1971 a 2000, en la estación urbana de Tablada (Sevilla).

Como puede observarse, las temperaturas medidas por la sonda norte son casi siempre superiores a las establecidas en las tablas oficiales, hecho que se ve acrecentado durante el periodo estival y otoñal, de mayo a octubre. Así, mientras en el resto de meses las diferencias de temperaturas están comprendidas entre $-0,5{ }^{\circ} \mathrm{C}$ y $1,0{ }^{\circ} \mathrm{C}$, durante este periodo las variaciones se encuentran entre los $2,0{ }^{\circ} \mathrm{C}$ y algo más de $3{ }^{\circ} \mathrm{C}$, lo que nos hace considerar este año como excepcionalmente caluroso.

\subsection{Diferencia de temperatura entre viviendas y zonas comunes}

Mediante las sondas de temperatura ambiente interior instaladas en las viviendas y en las zonas comunitarias del edificio, se han evaluado las diferencias de temperatura existentes. Estos saltos térmicos son valores importantes, y casi siempre difíciles de estimar, para evaluar las transferencias de calor (pérdidas o ganancias) entre estos recintos, especialmente cuando se determinan las cargas térmicas para el dimensionamiento de los sistemas de climatización.

En el edificio objeto de estudio, la temperatura de las zonas comunes a lo largo de todo el año se encuentran por debajo de la de las viviendas adyacentes, con saltos térmicos medios $(\Delta \mathrm{T})$ que oscilan entre $1{ }^{\circ} \mathrm{C}$ en verano y $3,5^{\circ} \mathrm{C}$ en invierno (Tabla 2 ).

Tabla 2

Saltos térmicos medios (viviendas-zonas comunes)

\begin{tabular}{|c|c|c|}
\hline $\begin{array}{l}\text { linpass } \\
\text { Ch: llk }\end{array}$ & 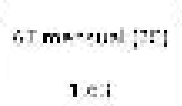 & \multirow{8}{*}{ 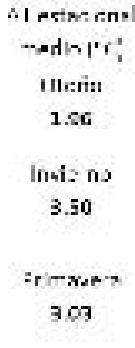 } \\
\hline h.on-2z & 229 & \\
\hline 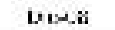 & S. Sii & \\
\hline EN: $C 9$ & 376 & \\
\hline $1+\mathrm{t}-4: 4$ & in & \\
\hline 11.109 & $\$ 28$ & \\
\hline$A x+4$ & $2: 1$ & \\
\hline Hus & 3.0 & \\
\hline $\operatorname{lu} x \cdot 5$ & 100 & \multirow{4}{*}{ 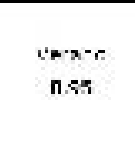 } \\
\hline Iut-: $:$ & $\ln 1$ & \\
\hline icsca & $0 \varepsilon 4$ & \\
\hline S*FFt:U & $1 \cdot \mathrm{h}$ & \\
\hline
\end{tabular}




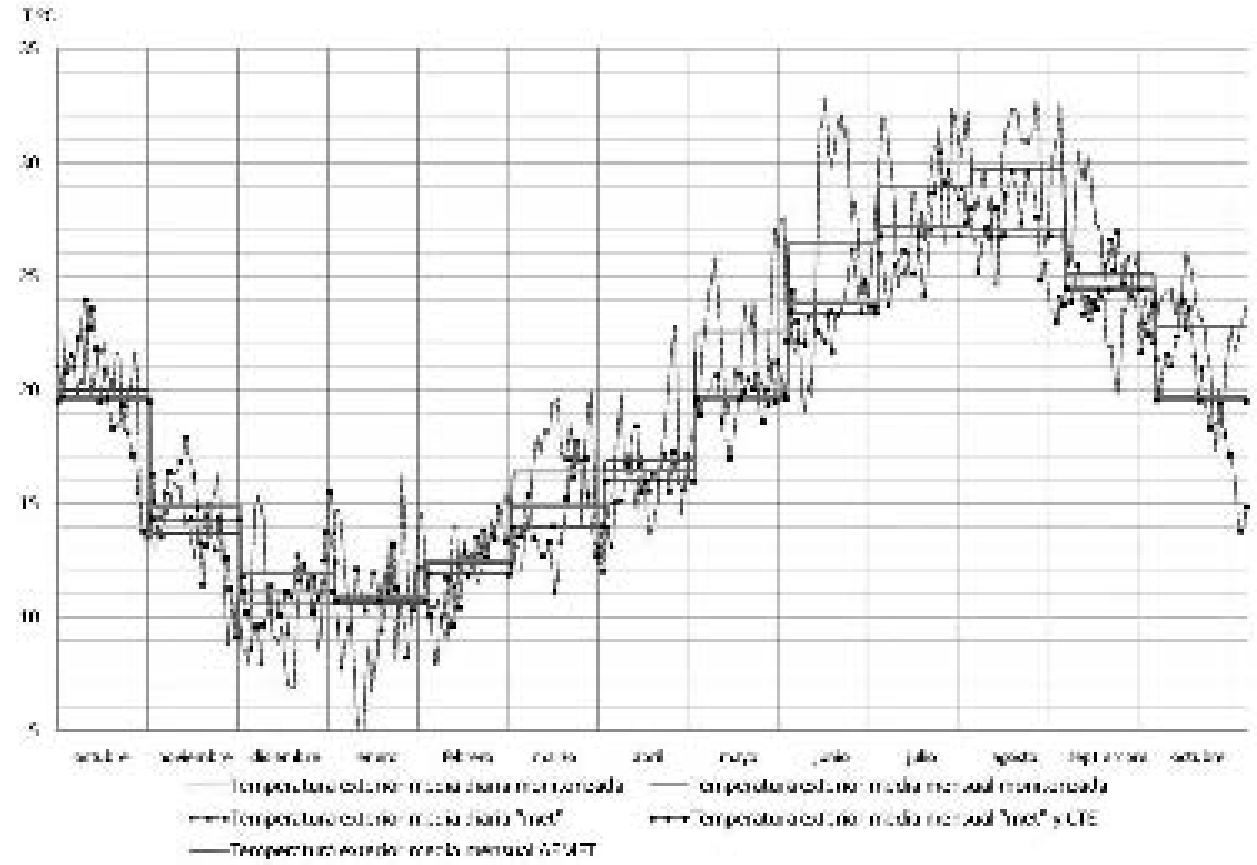

\subsection{Temperaturas ambientales interiores de vivienda}

La Tabla 3 (pág. siguiente), presenta las temperaturas medias mensuales registradas en el interior de las viviendas en función de su orientación.

En el período invernal, las viviendas con las temperaturas interiores medias más bajas han sido las orientadas al norte. A continuación, y en orden ascendente, se encuentran las orientadas al este, sur y oeste, estas últimas las más cálidas. En el período estival las claramente más calurosas son las orientadas al oeste (los cuatro meses). En el resto de orientaciones no se ha observado ningún patrón de comportamiento homogéneo, ya que los registros cambian de tendencia en los cuatro meses analizados.

\subsection{Niveles de concentración de $\mathrm{CO}_{2}$ en el interior de las viviendas}

Como parámetro indicador de la calidad del aire interior, y por tanto de la ventilación de las viviendas, se ha procedido a estudiar la diferencia de niveles de concentración de $\mathrm{CO}_{2}$ atmosférico exterior con los niveles interiores de las viviendas medidos en partes por millón (p.p.m.) (Tabla 4, página siguiente).

En las viviendas analizadas, anteriores a la entrada en vigor del CTE, el grado de permeabilidad al aire y los hábitos de ventilación de los usuarios nos permiten afirmar que los caudales de ventilación que se alcanzan garantizan una adecuada calidad del aire interior. La diferencia media anual de niveles de concentración de $\mathrm{CO}_{2}$ es de unas 150 p.p.m. que están muy por debajo del límite de 350 fijado (14) para la categoría I. Asimismo, la calidad del aire interior es sensiblemente mejor en el período estival que en el invernal.

\subsection{Temperatura de entrada del agua fría}

Se ha monitorizado la temperatura del agua fría en las tuberías de alimentación de los equipos de captación de energía solar para agua caliente sanitaria, valor que tiene indudable repercusión energética, pues influye en el salto térmico que deben facilitar los equipos para la obtención de la temperatura de consumo de agua caliente sanitaria.

En la Figura 6 (pág. 87) se muestran los valores medios mensuales obtenidos, junto con los valores facilitados por el Instituto de Diversificación y Ahorro de la Energía (IDAE) (15) y la norma UNE 94002/2005 (16) recogida en el Documento Básico HE-4: Contribución solar mínima de agua caliente sanitaria del CTE.

\subsection{Consumo eléctrico de viviendas}

Se han analizado los consumos eléctricos de las ocho viviendas monitorizadas, discriminando el consumo de la climatización del resto de los usos, lo que nos ha servido, entre otros fines, para establecer unos patrones de consumo tanto en días laborables como de fin de semana. En las Figuras 7 y 8 se presentan las gráficas que relacionan los consumos en un día medio laborable (lunes
5. Temperaturas exteriores (octubre 2008-octubre 2009). 
Tabla 3

Temperaturas interiores de viviendas. Valores medios mensuales según orientación

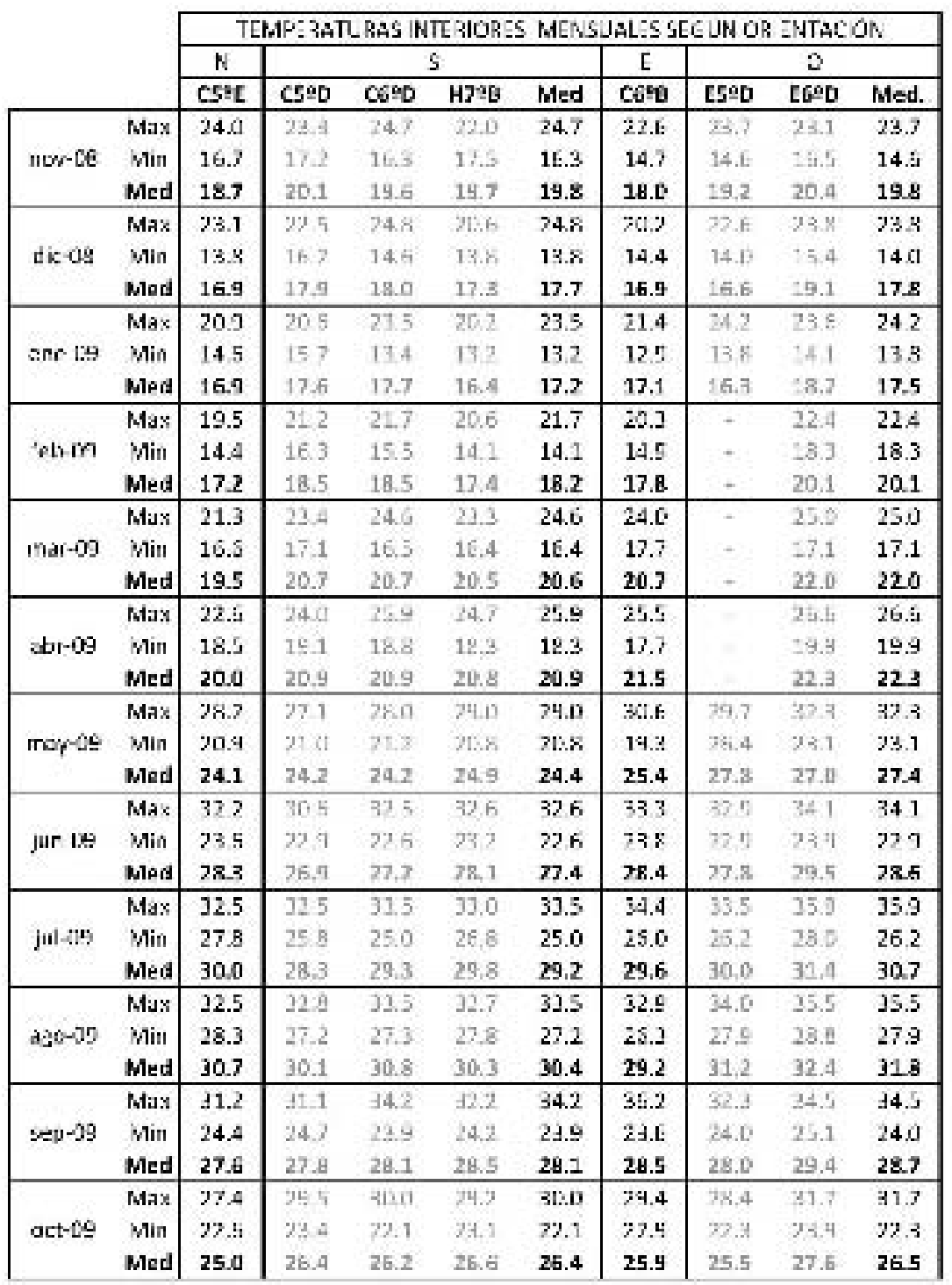

Tabla 4

Niveles de concentración de $\mathrm{CO}_{2}$ exteriores e interiores. Valores medios mensuales y estacionales

\begin{tabular}{|c|c|c|c|c|}
\hline Mes y aria & $\begin{array}{l}\mathrm{CO}_{2} \text { (p.p.m.) } \\
\text { Exterisr }\end{array}$ & $\begin{array}{c}\text { Co. fo.p.m.l } \\
\text { interior }\end{array}$ & $\begin{array}{c}\Delta \mathrm{CO}_{2} \text { |0.p.m.l } \\
\text { Mensual }\end{array}$ & $\begin{array}{c}\mathrm{SCO}_{2} \text { (p.p.m.' } \\
\text { Estacional }\end{array}$ \\
\hline Oc:-08 & 409 & 503 & 94 & \multirow{2}{*}{$\begin{array}{c}\text { Ctsia } \\
129\end{array}$} \\
\hline New 08 & 390 & 5.54 & 164 & \\
\hline D/c-08 & 339 & 585 & 297 & \multirow{3}{*}{$\begin{array}{c}\text { Invierno } \\
287\end{array}$} \\
\hline Ene-09 & 336 & 701 & 318 & \\
\hline Feb-09 & 208 & 632 & 245 & \\
\hline Mar (19) & $44 \%$ & $\mathrm{SDS}$ & 114 & \multirow{3}{*}{$\begin{array}{l}\text { arimauer } \\
\text { 109 }\end{array}$} \\
\hline$A b x-09$ & 395 & $\angle 98$ & 102 & \\
\hline May-0s & 235 & 502 & 107 & \\
\hline Juก- 09 & 295 & 507 & 112 & \multirow{4}{*}{$\begin{array}{c}\text { Verano } \\
83\end{array}$} \\
\hline Jul-c9 & 399 & 475 & 76 & \\
\hline मेgo-03 & 420 & 463 & 63 & \\
\hline sep 19 & $4 \% 1$ & -82 & 82 & \\
\hline & & ANUAL & 148 & \\
\hline
\end{tabular}



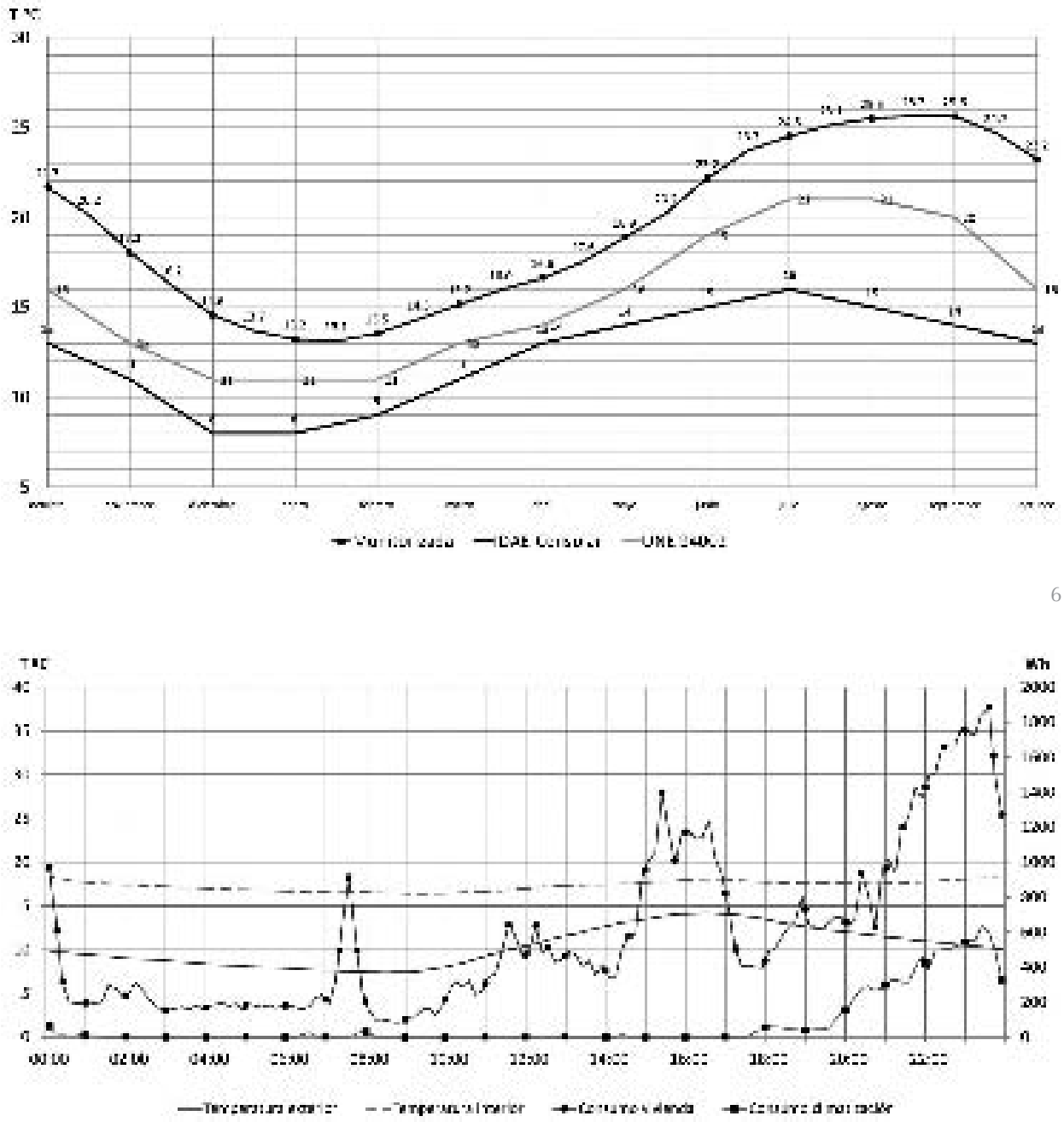

6. Temperaturas suministro agua fría. Datos quincenales (octubre 2008-octubre 2009).

7. Vivienda $\mathrm{H}-7^{\circ} \mathrm{B}$. Consumo eléctrico en un día medio laborable (Mes de diciembre).

8. Vivienda $\mathrm{H}-7^{\circ} \mathrm{B}$. Consumo eléctrico en un día medio laborable (Mes de junio).

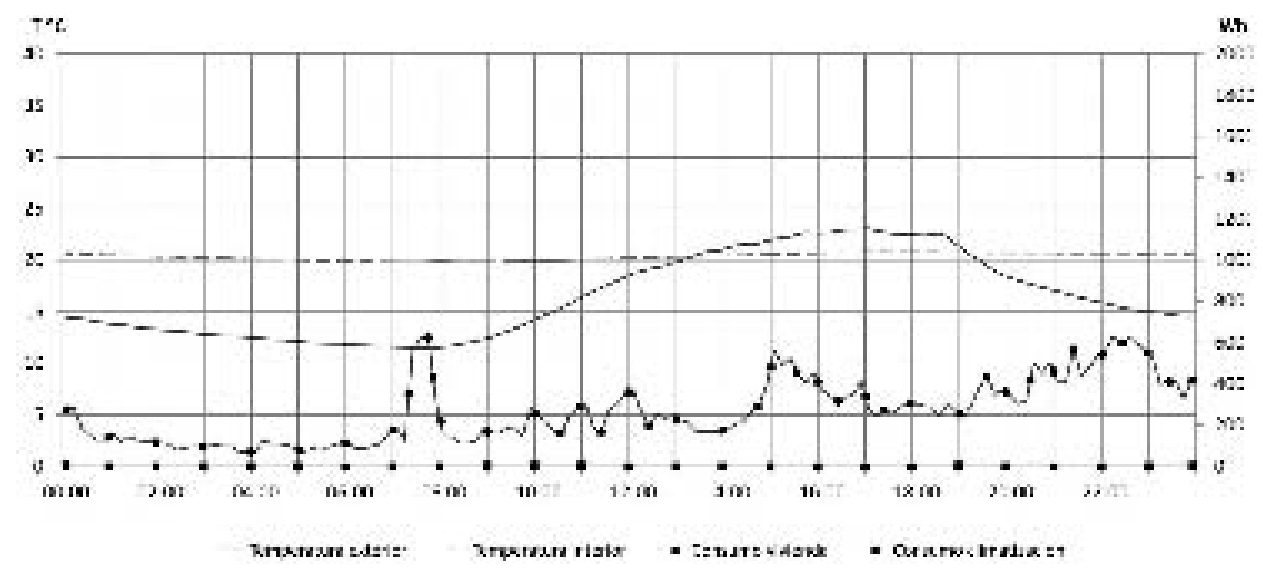

a viernes por ser los más representativos de la actividad doméstica habitual) en los meses de diciembre y junio, respectivamente, de una de las viviendas monitorizadas, en concreto la situada en el bloque $\mathrm{H}$ piso $7^{\circ}$ B. Por la relación que tienen esos consumos con la temperatura exterior e interior, en esas mismas figuras también se representan las temperaturas medias exteriores e interiores monitorizadas.
A partir del análisis de estas gráficas de consumo eléctrico, se han establecido unos patrones de consumo instantáneo (potencia) promediado mensualmente para todas las viviendas monitorizadas en las cuatro estaciones del año. Las Figuras 9 y 10 presentan los resultados para el período invernal y estival, respectivamente, de las ocho viviendas estudiadas. Al tratarse de consumos instantáneos diarios (media estacional), los valores 
9. Patrón de consumo eléctrico medio instantáneo diario (24h). Invierno.

10. Patrón de consumo eléctrico medio instantáneo diario (24h). Verano.
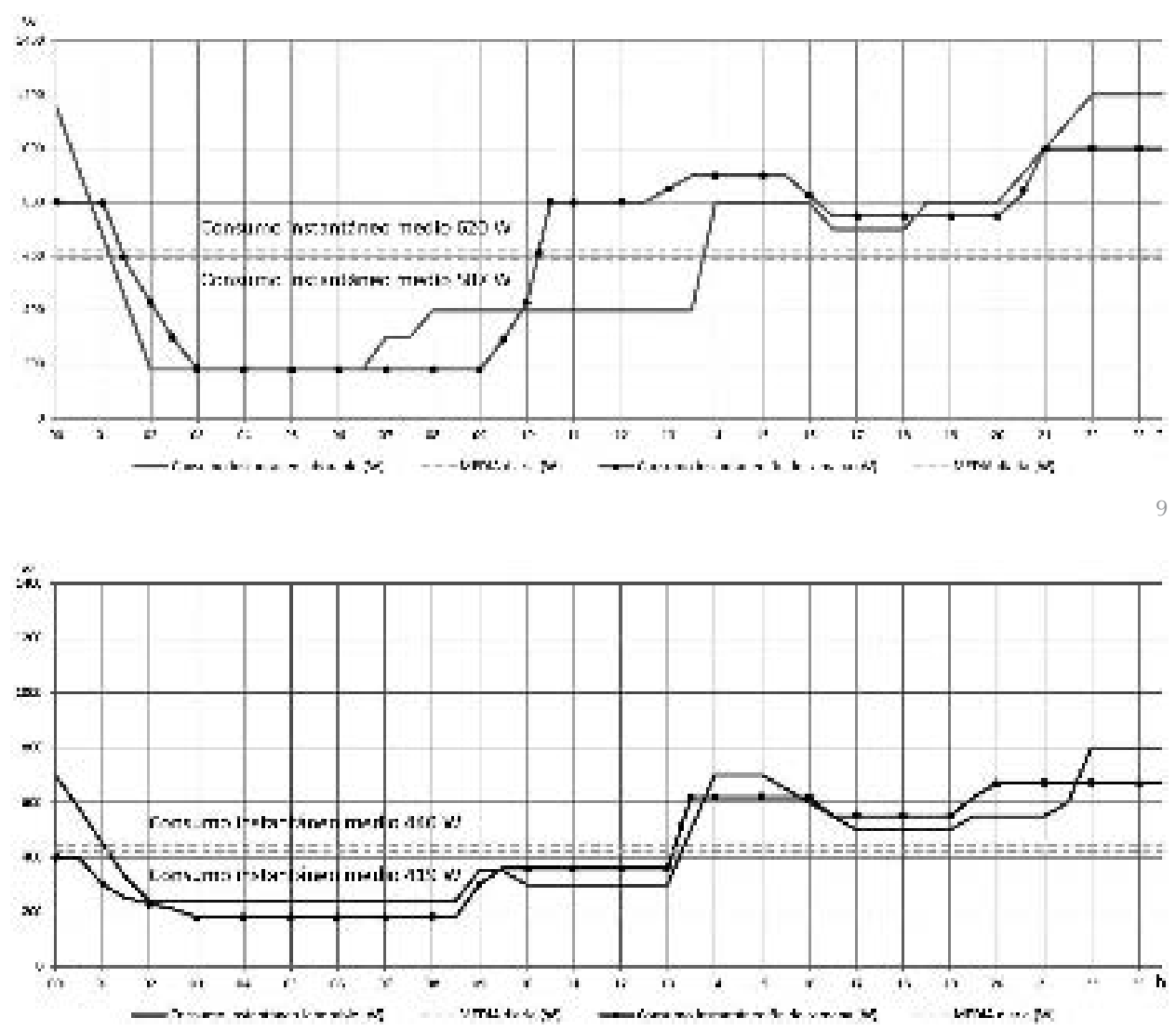

Tabla 5

Consumos instantáneos (potencia) medios de las ocho viviendas monitorizadas.

\begin{tabular}{|c|c|}
\hline TIPO DE CONSUMO Y ACTIVIDAD & $\begin{array}{l}\text { CONSUMO INSTANTANEO } \\
\text { (POTENCIA) MEDIO (W) }\end{array}$ \\
\hline Residual o stond'by. $\{0: 00$ a $7: 30 \mathrm{~h}\}$ & $180 \mathrm{~W}$ \\
\hline Comienzo actividad diurna $(7: 30$ a 9:00 h) & $\begin{array}{c}300-350 \mathrm{~W} \\
\text { (inverno } 400 \mathrm{~W} \text { ) }\end{array}$ \\
\hline Mañana $(9: 00$ a $14: 00 h)$ & $\begin{array}{c}350-400 \mathrm{~W} \\
800 \mathrm{~W} \text { (invierno on fin de semana) }\end{array}$ \\
\hline Almuerzo (14:CO a 15:30 h) & $\begin{array}{c}800-1000 \mathrm{~W} \text { (invierno) } \\
560-620 \mathrm{~W} \text { (iresto) }\end{array}$ \\
\hline Tarcle $(15: 30$ a $21: 30 \mathrm{~h}\rangle$ & $\begin{array}{l}750 w \text { (invierno) } \\
450-550 w \text { (resto) }\end{array}$ \\
\hline Noche $(21: 30$ a $0: 00 h)$ & $\begin{array}{c}1000-1200 \mathrm{~W} \text { (invierno) } \\
650-900 \mathrm{~W} \text { (́resto) }\end{array}$ \\
\hline
\end{tabular}

indicados en las gráficas son sensiblemente inferiores a la potencia puntual que frecuentemente se produce, al promediarse estadísticamente los momentos de demanda y reposo eléctricos.

El análisis permite distinguir una serie de zonas diferenciadas que pueden ser discrimina- das. En la Tabla 5 se presentan los consumos instantáneos residual o de stand-by (debido al funcionamiento continuado de electrodomésticos, como frigoríficos, o de equipos audiovisuales no desconectados totalmente de la red que se encuentran en estado de espera), así como los medidos en distintos períodos del día: comienzo de la actividad 
diurna, actividad matinal, almuerzo y actividades vespertina y nocturna. A diferencia de la impresión que se suele tener, los consumos eléctricos en el período invernal en este edificio situado en Sevilla, son sensiblemente superiores a los del estival. En días laborables de invierno, el consumo medio es un $25 \%$ superior al de los días de verano, mientras que en días festivos ese aumento llega a ser del 32\%.

Por otro lado, a partir del estudio de los consumos domésticos medios quincenales se han obtenido los consumos instantáneos máximos estivales e invernales en comparación con los consumos alcanzados en las estaciones intermedias que se podrían considerar como consumos funcionales (consumos instantáneos mínimos anuales). Este consumo funcional nos da, por diferencia, el aumento de consumo instantáneo estacional estival e invernal debido a los equipos y sistemas de climatización (Figura 11).

\subsection{Consumos de agua fría sanitaria (AFS)}

Para el estudio de los consumos de agua fría doméstica, se presentan los valores medios de las lecturas de los contadores individuales de las viviendas estudiadas. Se ha contemplado un periodo anual desde el 12 de noviembre de 2009 hasta el 6 de noviembre de 2009 con los siguientes datos de consumo medidos en $\mathrm{dm}^{3}$ /día · usuario (Tabla 6). De los resultados puede observarse cómo el consumo medio de este tipo de viviendas oscila entre los 80 y 100 litros diarios por habitante. El período de menor consumo corresponde a la primavera y los consumos más altos de dan en los períodos estival y otoñal.

\section{ENCUESTAS A USUARIOS SOBRE HÁBITOS DE OCUPACIÓN Y DE CONSUMO}

Con el objetivo de conocer los hábitos, ocupación y consumos eléctricos y de agua de este tipo de viviendas, se han elaborado dos tipos de encuestas. La primera de ellas está referida a la época comprendida entre la mitad del otoño y la mitad de la primavera, periodo al que llamaremos de "invierno" y la segunda, al comprendido entre mediados de la primavera y mediados de otoño, al que denominamos "verano". Ambos tipos poseen los siguientes seis apartados: (I) Datos de la Unidad Familiar; (II) Ocupación media diaria por habitante; (III) Horas de utilización de los equipos audiovisuales; (IV) Horas de uso de los ordenadores; (V) Horas de uso de aparatos de calefacción/refrigeración; y (VI) Hábitos de los ocupantes. En la Figura 12 (pág. siguiente) se reproduce parcialmente dicho modelo de encuesta.

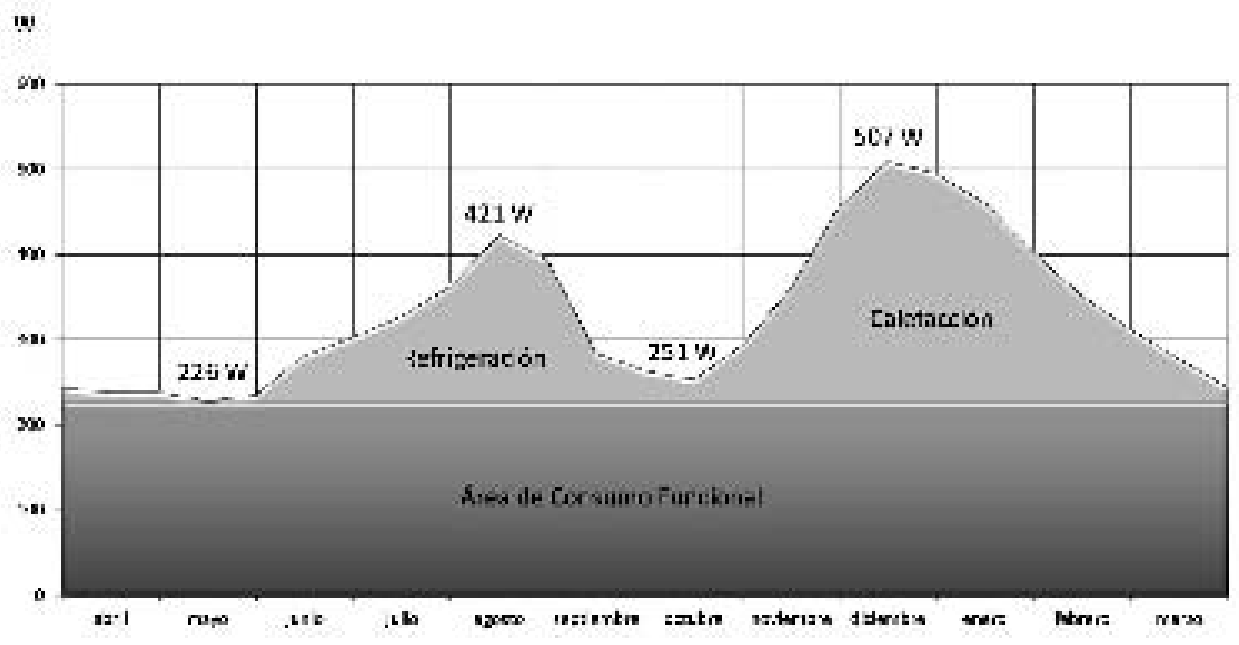

11. Consumos instantáneos para un periodo anual.

Tabla 6

Consumos de AFS en las viviendas monitorizadas ( $\mathrm{dm}^{3} /$ día-usuario).

\begin{tabular}{|c|c|c|c|c|c|c|c|c|}
\hline $\begin{array}{l}\text { "echa } \\
\text { lecturá }\end{array}$ & $\begin{array}{l}\text { Vivienta } 1 \\
\text { (2 vesd } 2 \text { ) }\end{array}$ & $\begin{array}{l}\text { Wvimrid: } 2 \\
\text { : ussariol }\end{array}$ & $\begin{array}{l}\text { Viviendil } 3 \\
\text { i- Lasdicy }\end{array}$ & $\begin{array}{l}\text { Viviendis } 4 \\
\mid 2 \text { usuerius } \mid\end{array}$ & $\begin{array}{l}\text { Viviendil } 5 \\
\text { 2 usueriusl }\end{array}$ & $\begin{array}{l}\text { Viviendia } 6 \\
\text { (1 usJaricsl }\end{array}$ & $\begin{array}{l}\text { Vivienda } 7 \\
\text { (2 vosar ius) }\end{array}$ & Promedlos \\
\hline $11 / 02 / 2009$ & 944 & 556 & 233.3 & 100.0 & 77.8 & 47,2 & 83,3 & 98.8 \\
\hline $07 / 05 / 2009$ & 88.4 & 77.8 & 38.9 & 1444 & 6111 & 44,4 & 66,7 & 81.7 \\
\hline 14/00/2009 & 111.1 & 77.8 & 133.3 & 155.5 & 100.0 & 47.2 & 100.0 & 103.6 \\
\hline $06 / 11 / 2009$ & 88.9 & 55.6 & 2111 & 133.3 & 105.6 & 47.2 & 83.3 & 103.6 \\
\hline
\end{tabular}




\section{PROYECTO EFFICACIA}

ENCUESTA SOERE HÁBITOS Y OCUPACIÓN DE LAS VIVIENDAS (INVIERNO)

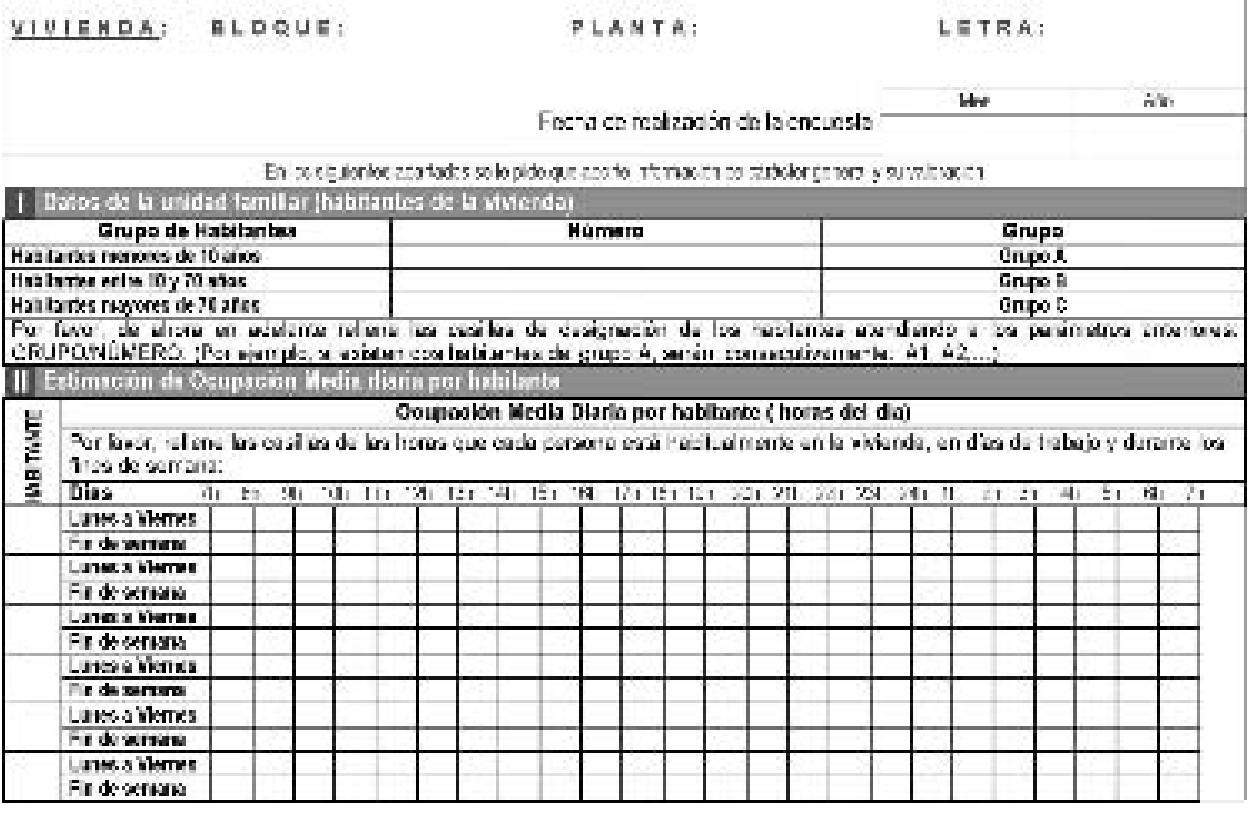

12. Modelo de encuesta de hábitos de consumo.

13. Ocupación media diaria en invierno y verano. Días laborables (lunes a viernes)
Se han realizado un total de 67 encuestas en invierno y otras tantas en verano (134 en total) incluidas las de las viviendas monitorizadas, y se ha realizado un tratamiento estadístico de las mismas por apartado, obteniendo curvas de ocupación diaria, de uso de aparatos audiovisuales, de ordenadores, de utilización de sistemas de calefacción/ refrigeración, así como la estimación media de los tiempos que los usuarios le dedican a cocinar, según el tipo de energía consumida para su proceso (gas o electricidad) $y$, por último, la estimación media semanal del número de veces que los propietarios se duchan o bañan y las que utilizan los electrodomésticos principales.

\subsection{Hábitos de ocupación}

En las Figuras 13 y 14 se muestran las gráficas de ocupación media diaria, en días laborables y fines de semana, respectivamente, en comparación con el protocolo utilizado por el programa informático LIDER. Este programa, establecido por el documento básico HE 1 de CTE para la aplicación de la opción general de la limitación de demanda energética de los edificios, utiliza el mismo protocolo de ocupación media en la vivienda tanto para el invierno como para el verano. Comparando los resultados de ocupación media diaria de las viviendas, se observa que en días laborables la ocupación recogida en

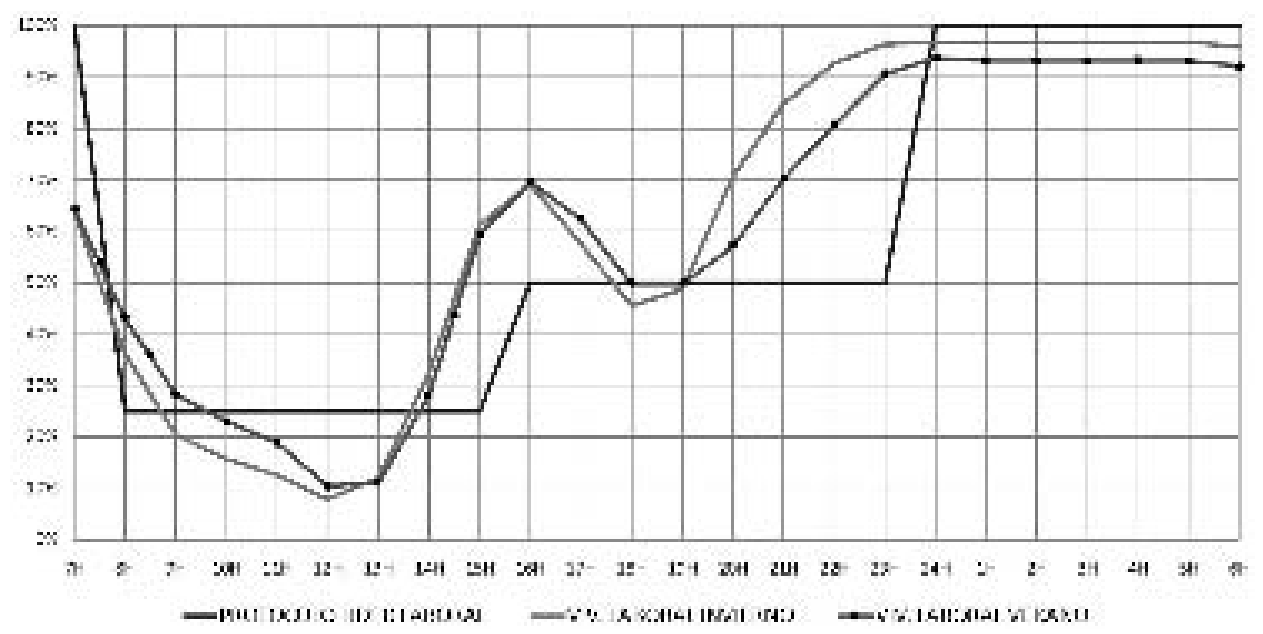




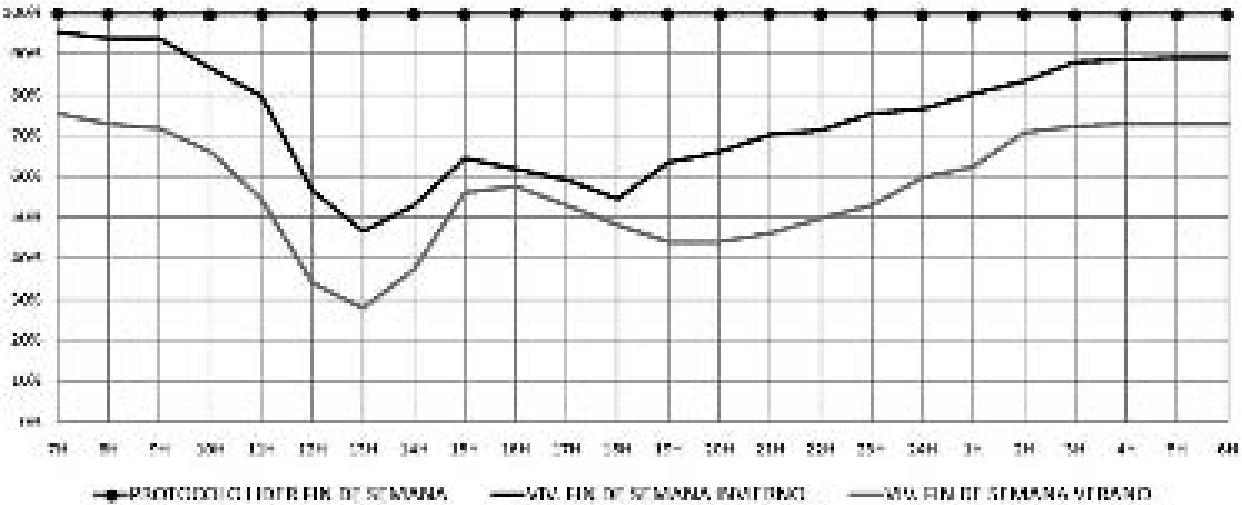

14

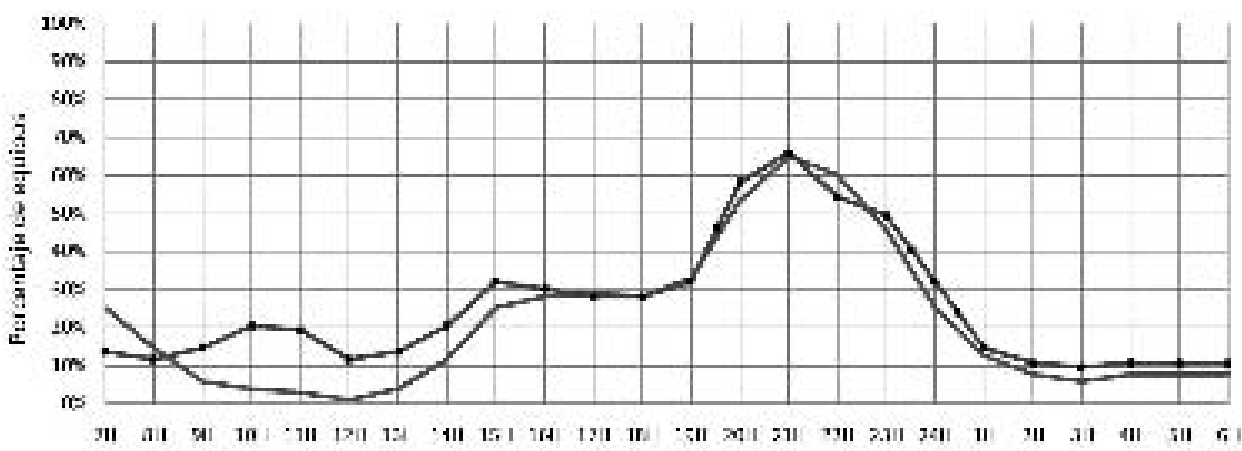

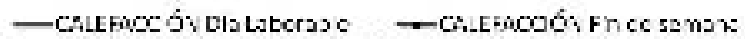

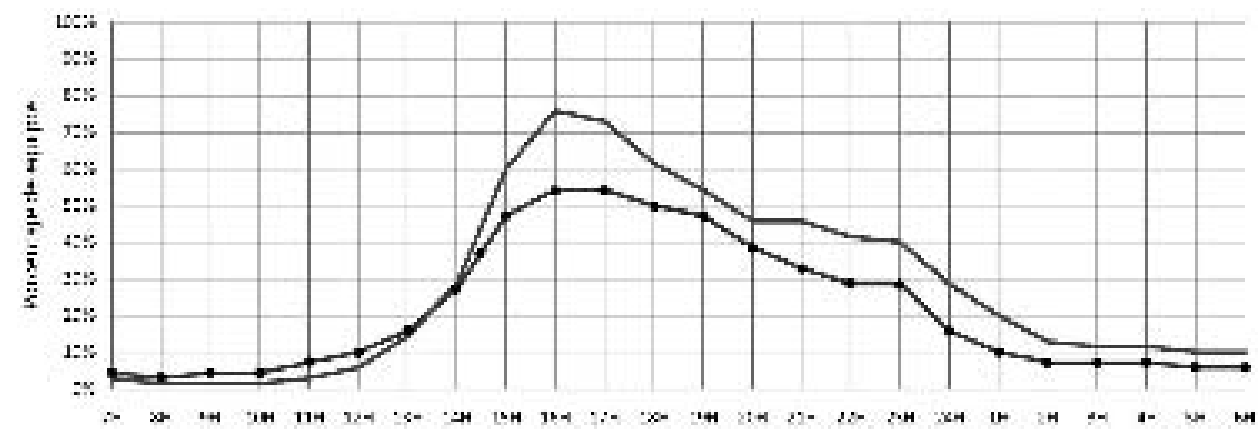

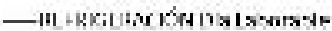

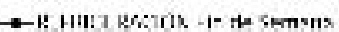

las encuestas y las establecidas oficialmente, tanto para invierno como para verano, presentan bastante aproximación, excepto en la franja horaria entre las 20:00h y las 23:00 h, en la que el programa LIDER considera un porcentaje menor de ocupación. Por el contrario, en días festivos existe una importante diferenciación debido a la hipótesis de ocupación tan simplificada que utiliza el programa oficial, al considerar una ocupación total y continuada durante todo este periodo.

\subsection{Uso de equipos de calefacción/ refrigeración}

Las Figuras 15 y 16, muestran la utilización de los aparatos de calefacción y refrigera-

\section{Ocupación media diaria en in- vierno y verano. Fines de semana. \\ 15. Hábitos de uso de calefacción. \\ 16. Hábitos de uso de los equipos de refrigeración.}

ción, reflejada en las encuestas de los usuarios.

En el caso de la utilización de los equipos de calefacción, se observa una clara diferenciación entre días festivos y laborales, tanto en el comienzo de la actividad diurna como durante las mañanas. En el resto de horas, la utilización entre días laborables y festivos apenas presenta diferencias, dándose la punta de mayor uso durante el final de la tarde y noche, en clara correspondencia con los datos monitorizados de consumo.

En cuanto al uso de los equipos de refrigeración, como cabía esperar, las horas puntas de utilización se dan en las horas centrales 
del día, tanto en festivos como en laborables, coincidiendo con las máximas temperaturas exteriores. Estos resultados también tienen coincidencia con los consumos analizados.

\section{CONCLUSIONES}

I. El periodo meteorológico monitorizado ha sido atípico en comparación con los anteriores (especialmente caluroso en verano y frío en invierno), existiendo divergencias con los modelos climáticos oficiales. Si esta tendencia se mantiene, sería necesario una actualización de los ficheros climáticos que utilizan las herramientas normativas informáticas para obtener un correcto análisis energético.

II. Condiciones interiores de las viviendas monitorizadas.

a. En general, los ambientes interiores de las viviendas monitorizadas son poco confortables térmicamente, presentando altas temperaturas en verano y bajas en invierno.

b. En invierno y verano, las viviendas con peor comportamiento térmico han sido las orientadas al norte y oeste, respectivamente. En el resto de orientaciones las diferencias no son tan acusadas, si bien las condiciones interiores siguen fuera de los rangos de confort. Analizadas anualmente, las viviendas orientadas al sur son las que presentan temperaturas más próximas a la media global, y por tanto las que menor demanda de energía presentan en relación a este parámetro.

c. En la mayoría de las situaciones no se alcanzan los valores de temperatura de consigna aunque se utilicen los equipos de climatización.

d. La envolvente térmica del proyecto de viviendas de Cross, sin ser especialmente eficaz, puede considerarse razonable desde el punto de vista térmico. Por ello, este mal comportamiento es achacable a tres aspectos principales: d1) Diferencias entre la envolvente térmica real y el modelo energético, como consecuencia de los procesos de ejecución (estas diferencias se hicieron patentes mediante las realización de ensayos in situ de termografía, presurización y pruebas para la determinación de la transmitancia térmicas $U$ ); d2) Existencia de entrada de aire incontroladas (infiltraciones, huecos de instalaciones,...) debido tanto a la calidad de los materiales (carpinterías y cajas de persiana, fundamentalmente) como a los sistemas constructivos empleados (particiones y trasdosados de entramado autoportante). No obstante, este aspecto es favorable para mantener una adecuada calidad del aire al producirse una ventilación continuada, tal y como se ha podido comprobar en los trabajos de monitorización; y d3) Mala eficiencia de los equipos de calefacción utilizados por los usuarios, fundamentalmente los de calentamiento localizado (tipo brasero o mesa camilla), sin que se invierta energía apenas en las masas internas, por lo que no se alcanza una adecuada estabilidad térmica.

e. Para alcanzar unas adecuadas condiciones de confort interior y un bajo consumo energético, entendemos que es básico dotar a la vivienda de: e1) sistemas de climatización adecuados, y e2) mecanismos de ventilación controlados cuya respuesta sea proporcional o ajustada a los procesos de contaminación interior y aprovechen los momentos de mejores condiciones exteriores para los ciclos de ventilación, evitando que haya una relación tan estrecha entre la evolución de temperaturas exteriores e interiores, comportamiento típico de espacios muy ventilados.

f. Las diferencias de temperatura observadas entre el interior de las viviendas y las zonas comunes comunitarias, son relativamente pequeñas por lo que no es un punto relevante desde el punto de vista térmico. No obstante, dadas las nuevas exigencias de aislamiento fijadas por el CTE-HR: Protección frente al ruido, este punto carecería de importancia.

III. Para garantizar una adecuada calidad del aire interior se necesita una buena ventilación continua, haciéndose de forma controlada para que sea compatible con el control térmico, confort y ahorro energético. Por ello, y con el objeto de mantener unas adecuadas condiciones térmicas interiores, se deberá prestar especial atención a las futuras viviendas ejecutadas bajo el CTE-HS-3, debido a los niveles de ventilación continúa que se van a generar por aplicación de la citada normativa. Además, dada la evolución de los hábitos de usos de los usuarios, los procedimientos de ventilación manual o voluntarios son cada vez menos efectivos. Con estos la calidad del aire empeora en invierno, tal y como se demuestra en los datos de $\mathrm{CO}_{2}$ y de humedad relativa monitorizados, siendo conveniente utilizar sistemas más selectivos que ventilen cuando sea realmente necesario.

IV. Las temperaturas de red medidas a la entrada de los sistemas solares, durante el período de monitorización, están por encima de las temperaturas de AFS de referencia. El considerar, a efectos de dimensionamiento de los sistemas solares, las temperaturas medidas en comparación con las de referencia oficiales, permitiría reducir la demanda de producción térmica del ACS entre un 6 y un $14 \%$, dependiendo si la demanda se compara con la resultante de tomar las temperaturas de la norma UNE o de IDAE Censolar, respectivamente. Además, la energía cedida por los sistemas auxiliares se reduciría en la misma proporción, aproximadamente. 
V. Consumo de electricidad. Se ha constatado un mayor consumo eléctrico en invierno que en verano debido a la inadecuada elección de los equipos de calentamiento por parte de los usuarios. Por otro lado, también se han cuantificado los consumos funcionales (principalmente electrodomésticos) comprobándose que suponen una parte significativa de los totales. Por ello, una adecuada elección y funcionamiento de los mismos redundará en una significativa reducción del consumo eléctrico global, ya que si bien sus consumos específicos no suelen ser altos, éstos se producen de forma continuada en la operación de la vivienda, tal y como ha podido comprobarse con los sistemas de monitorización, por lo que se pueden identificar como un objetivo relevante de ahorro energético en la vivienda.

VI. Consumo de agua. En las viviendas analizadas se ha observado que, en general, los consumos conjuntos de AFS y ACS están en unos rangos medios-altos. El utilizar sistemas de distribución de ACS centralizada, sin sistema de control de consumo individual, produce puntuales gastos elevados, tanto de caudal de agua como de la energía asociada a su preparación, ya que, si bien esta producción proviene del sistema solar, siempre se requiere un apoyo auxiliar, sobre todo en los consumos realizados a primera hora de la mañana

VII. Mediante la aplicación del proceso de monitorización y encuestas de los ocupantes, se ha comprobado que las viviendas presentan un alto índice de variabilidad en sus comportamientos operativos, alejados de forma significativa de los establecidos en los procesos normativos (procedimiento LIDER/CALENER).

VIII. La monitorización y la realización de encuestas a los inquilinos revelan unos hábitos de uso y operacionales en las viviendas de promoción pública, derivados del cambio de modelo y reducción del número de componentes de las tradicionales unidades familiares y de la incorporación masiva de la mujer al mundo laboral, que tienen un claro reflejo en las condiciones ambientales y de consumo energético de las viviendas y, por extensión, de los edificios. Esos cambios no han sido reflejados en las normativas vigentes sobre construcción, que parecen ser consecuencia de hábitos de ocupación y consumo claramente en obsolescencia.

IX. En todo caso, se constata un nivel de ocupación habitual de las viviendas claramente inferior al estimado en los procedimientos de análisis, lo que tiene una especial influencia sobre el peso específico real de las demandas de calefacción y refrigeración, siendo en la realidad inferior a los modelos propuestos. Este aspecto debe ser tenido en cuenta al desarrollar estrategias de ahorro en la demanda, ya que los resultados reales pueden ser inferiores a los estimados. Este aspecto queda reforzado por la falta de cultura de acondicionamiento de los habitantes de las viviendas, utilizando habitualmente tratamientos puntuales de los espacios en tiempos breves, no manteniendo la vivienda en condiciones de consigna (de nuevo entra en discrepancia con el modelo oficial).

$X$. Existe un importante potencial de ahorro de consumo de energía eléctrica en viviendas, principalmente derivados de sus instalaciones de calefacción/climatización.

XI. En general los usuarios tienen una mala percepción -muy distorsionada- de sus hábitos de consumo de energía y otros servicios. Dar a conocer a los usuarios esa información, en combinación con la que proporcionaría la introducción de dispositivos de lectura de esos consumos en las viviendas (p.e. en tiempo real), permitiría que esos usuarios realicen acciones de retroalimentanción a los sistemas energéticos, lo que derivaría indefectiblemente a la reducción de su consumo.

\section{AGRADECIMIENTOS}

Los autores de este artículo, y el resto de investigadores del proyecto Efficacia, agradecen a la Empresa Municipal de Vivienda, Suelo y Equipamiento de Sevilla (EMVISESA), SODINUR S.L. y a la Corporación Tecnológica de Andalucía (CTA), la financiación de esta investigación y hacer factible el desarrollo de la misma.

\section{BIBLIOGRAFÍA}

(1) International Energy Agency Demand-Side. Subtask 1. Smaller Customer Energy Saving by End Use Monitoring and Feedback. EA Technology, Chester, UK, 2005.

(2) Bakker, E.J.: "Ecobuild Reseach: full-scale testing of innovative technologies for energy efficient houses". ECN, 2004.

(3) Sijpheer N.C. et al. "Integral energy research in buildings: Research and development with full scale research facility". ECN, 2005.

(4) Wood, G y Newborough, M. "Dynamic energy - consumption indicators for Domestic Appliances: Enviroment, Behaviour and Design. Energy and Buildings 1537 (2003), pp. 1-21 (2). 
(5) Energy Saving Trust Ltd. Homes Energy Efficiency Database (HEED) Evaluation Summary 2005-6, March 2006.

(6) Baranowsky, A.y Ferdyn-Grygierek, J. "Integrated simulation of heat demand and air exchange in a multifamily building". Department of Heating, Ventilation and Dust Removal Technology, Silesian University of Technology, Gliwice, Poland (2003).

(7) National Agency for Enterprise and Housing. "Monitoring of Torzhkovskaya 16 St. Petersburg Final report". Copenhagen, 2004.

(8) Turégano, J.A et al. "La experiencia del Parque Goya. Inicativas, desarrollo, resultados. Dirección General de Vivienda y Rehabilitación. Zaragoza, 2003.

(9) Heras Celemín, Ma del Rosario et al. "Evaluación del CIEMAT: Comportamiento energético de viviendas de la EMVS". Era Solar: Energías renovables, ISSN 0212-4157, nº 135, 2006, pp. 68-75.

(10) Giancola, E. et al. "Energetic Evaluation in Real Condition of Use Housing". 2nd PALENC Conference and 28th AIVC Conference on Building Low Energy Cooling and Advanced Ventilation Technologies in the 21st Century, September 2007, Crete island, Greece.

(11) Metasys: Sistema remoto de gestión y automatización de instalaciones en edificios. Johnson Controls, Inc. 2005.

(12) Norma UNE-EN ISO 7726:2002: Ergonomía de los ambientes térmicos. Instrumentos de medida de las magnitudes físicas.

(13) Valores medios mensuales recogidos en la tabla G.2 "Datos climáticos mensuales de capitales de provincia" del DB HE-1 Limitación de la demanda energética, del Código Técnico de la Edificación (CTE), coincidentes con el archivo climático "met", utilizado para la certificación eficiencia energética de los edificios.

(14) Norma UNE: 15251:2008: Parámetros del ambiente interior a considerar para el diseño y la evaluación de la eficiencia energética de edificios incluyendo la calidad del aire interior, condiciones térmicas, iluminación y ruido.

(15) Temperatura mínima media de la red general en ${ }^{\circ} \mathrm{C}$, obtenida a partir de medidas directas. Elaborada por el Instituto de Diversificación y Ahorro de la Energía (IDAE) y el Centro de Estudios de la Energía Solar (CENSOLAR).

(16) UNE 94 002: 2005 “Instalaciones solares térmicas para producción de agua caliente sanitaria: Cálculo de la demanda de energía térmica". 